\title{
Feasibility Study for Recovering Waste Heat in the Steelmaking Industry Using a Chemical Recuperator
}

\author{
Nobuhiro MARUOKA, Toshio MIZUOCHI, ${ }^{1)}$ Hadi PURWANTO and Tomohiro AKIYAMA \\ Department of Chemical Engineering, Graduate School of Engineering, Osaka Prefecture University, 1-1, Gakuen-cho, Sakai, \\ Osaka 599-8531 Japan. E-mail: maruoka@chemeng.osakafu-u.ac.jp \\ 1) Formerly at Osaka Prefecture University, now at JFE Steel Corporation.
}

(Received on July 14, 2003; accepted in final form on September 1, 2003)

\begin{abstract}
This paper studies the possibility of developing a new heat recovery system from various hot wastes generated by the steelmaking industry, by utilizing the endothermic heat of reaction instead of sensible heat. In the proposed system, the waste heat of the gas was first stored using a Phase Change Material (PCM), and then supplied to an endothermic, methane-steam reforming reaction (MSR) as a heat source. The molten slag was granulated using a rotary cup atomizer (RCA) and the sensible heat of the slag was recovered using MSR. A heat and material balance model was developed to evaluate this system and to predict all its operating data. An exergy analysis and an economic evaluation were conducted on the basis of the predicted data. The results showed that the exergy loss in the proposed system was only $15 \%$ from the total exergy losses in the conventional system, and that the annual cost benefit of the proposed system totaled US\$ 409 million from heat recovery, and US\$1945 million from slag granulation.
\end{abstract}

KEY WORDS: steelmaking; high temperature waste heat recovery; phase change material; rotary cup atomizer; endothermic reaction; economic evaluation; exergy analysis; methane steam reforming; chemical recuperator; hydrogen generation.

\section{Introduction}

The Japanese steelmaking industry consumes as much as $11 \%$ of the total primary national energy, and releases $5 \%$ of it in the form of waste heat, which gives rise to environmental problems. Thus, several studies have been conduct$\mathrm{ed}^{1-16)}$ to evaluate energy requirement, propose a new system, and design a new equipment for heat recovery, to enable energy conservation and decrease carbon dioxide emission in the steel industry. As a result of two major oil crises, many energy conservation methods have been introduced. However, no process has been identified to recover thermal energy from molten slag, and the hot waste gas discharged by blast furnaces (BF), LD-converters (LDC), and electric arc furnaces (EAF), in spite of its huge potential. ${ }^{6}$ The extremely high temperature of such wastes prevents their efficient recovery by conventional technology.

An earlier study proposed a new heat storage medium with large latent heat, called the 'Phase Change Material' (PCM) ${ }^{10-16)}$ for efficient recovery of intermittently emitted, high temperature waste heat such as that produced by combustion gas. The results ${ }^{11,12)}$ showed that intermittently emitted waste heat such as LDC gas changes into a constant and continuous heat source. Additional studies have reported a new slag granulation method using a Rotary Cup Atomizer $(\mathrm{RCA})^{9)}$ without water impingement. The results also showed that the RCA could produce fine slag particles less than $1 \mathrm{~mm}$ in diameter. The main advantage of this method, when compared to conventional water granulation, is that steam, polluted water, and hydrogen sulfide are not generated.

Recently, researchers have been focusing on a new heat recovery system that uses an endothermic reaction ${ }^{4,6,8,11,12}$ ) instead of sensible heat. This method is attractive because it facilitates the direct recovery of waste heat without any decrease in its existing temperature. The conventional method based on sensible heat storage is an indirect process that uses ceramics or water, etc., and requires an additional heat exchange. However, the new process is based on the concept that an endothermic reaction such as methane-steam reforming can be combined with high temperature waste heat to convert its thermal energy into chemical energy. The steam reforming of methane, which is a direct reduction process $^{1)}$ for producing hydrogen and carbon monoxide is essential to the chemical and ironmaking industry. The hydrogen and carbon monoxide gases generated can be used to synthesize methanol. ${ }^{3,11,12)}$ This is significant since the demand for methanol as a vehicle fuel, or as a hydrogen source for a fuel cell, or in other applications, is increasing sharply. Since an endothermic reaction is a key phenomenon in most industries, a large amount of fossil fuel can be saved by directly combining it with waste heat.

From the viewpoint of energy cascade utilization, ${ }^{1,2,5,12)}$ it is important to use high temperature waste heat as a heat source in the chemical industry. However, it can not be implemented in the steelmaking industry due to a lack of information on the subsequent economic and environmental effects. Therefore, the aim of this study is to evaluate a new 
waste heat recovery system for the steelmaking industry using an endothermic reaction. The study includes an exergy analysis and an economic evaluation to assess the entire process. The results will indicate the possibility of realizing a process for co-producing steel and hydrogen. Furthermore, the proposed system will contribute in promoting energy conservation in the steelmaking industry by reducing the amount of energy consumed in the production of hydrogen in the chemical industry.

\section{Heat Recovery Using an Endothermic Reaction}

The sensible heat method is commonly used for heat recovery, for example, in the generation of hot water or steam from the waste heat of an incinerator. In this process, the heat from high temperature wastes is used as a low energy resource with low quality. According to the energy theory, high temperature waste heat should be used as a high temperature heat source. Therefore, the conventional method of utilizing high temperature waste heat by generating hot water or steam is inefficient.

In fact, in various industries, the key reaction is always endothermic, and fossil fuel is consumed to obtain the exothermic heat of combustion. Therefore, if waste heat is combined with the desired endothermic reaction, it will facilitate significant energy conservation. In this study, the methane-steam reforming reaction is selected as a combination process ${ }^{8,11,12)}$ for heat recovery from high temperature waste gas and molten slag. This process uses the following reaction:

$$
\mathrm{CH}_{4}+\mathrm{H}_{2} \mathrm{O} \rightarrow \mathrm{CO}+3 \mathrm{H}_{2} \quad \Delta H_{298}=206 \mathrm{~kJ} / \mathrm{mol} \ldots \ldots
$$

This reaction is energy consuming, and is extensively used in direct reduction and methanol production processes. Moreover, this reaction is also used for the production of hydrogen from natural gas. Being an environmentally friendly resource, hydrogen is considered an alternative source of energy and its demand is expected to surpass that of fossil fuels. The combination process proposed above has the potential to generate hydrogen by utilizing the reaction heat from high temperature waste such as exhaust gas and steelmaking slag.

\section{Proposed Systems}

\subsection{Heat Recovery from Waste Gas}

Conventionally, in the steelmaking industry, high temperature waste gases over $1700 \mathrm{~K}$ are released from LDC and EAF. As the process is batch type, the hot gas is discharged periodically during the operating period. Unfortunately, despite its potential, the sensible heat of such high temperature gases can not be recovered and are wasted due to technical difficulties involved in heat recovery.

From the viewpoint of the exergy theory, the temperature of the waste gas should be maintained as high as possible for the heat to be effectively utilized. This is because the potential to effectively utilize thermal energy is greater at higher temperatures. An earlier report ${ }^{6,11,12)}$ concluded that thermal energy of LDC gas with temperatures over $1300 \mathrm{~K}$, should be supplied to endothermic processes that require it. These include coal gasification, natural gas reforming, limestone decomposition, etc. It should never be used to generate hot water at $353 \mathrm{~K}$ or steam at $473 \mathrm{~K}$, and thereby undergo such a temperature drop. According to the thermodynamic theory, exergy is lost once the temperature drops even though the heat loss is negligible.

LDC and EAF release waste gases only during the operating period. The utilization of latent heat between the solid and liquid phase, using a PCM, is very useful for recovering and storing the intermittently released gas, and then supplying it as a heat source with a constant temperature, to another process. ${ }^{11)}$ In the proposed system, a reaction tube containing the PCM is placed over the furnace as shown in Fig. 1. The PCM in the reaction tube melts during the operating period and stores the waste heat. The stored heat is supplied to the endothermic reaction of the methane-steam reforming process during both the operating and discharging periods of the LDC or EAF.

In a corresponding paper, ${ }^{11)}$ it was concluded that the developed PCM balls can store high temperature waste heat, release the heat stored with a constant temperature, and also act as excellent catalysts in the steam reforming process. These findings suggest that the proposal of a new process for recovering heat from waste gases by using the latent heat of the PCM and the endothermic heat of the methanesteam reforming process is acceptable.

\subsection{Heat Recovery from Steelmaking Slag}

Steelmaking furnaces such as BF, LDC and EAF, discharge a large amount of high temperature molten slag as waste. Presently, the slag is treated conventionally by impinging it with a large amount of water for the granulation and glassification processes. However, this method has the following problems:

(1) A large amount of water is required to granulate high temperature molten slag.

(2) An alkaline element in the slag pollutes the water.

(3) Sulfide from the slag is emitted into the air during the water quenching process.

(4) After water quenching an additional process is needed to make the slag dry.

(5) The thermal energy of the high temperature slag is not recovered and therefore wasted.

To solve these problems, the authors, in their previous

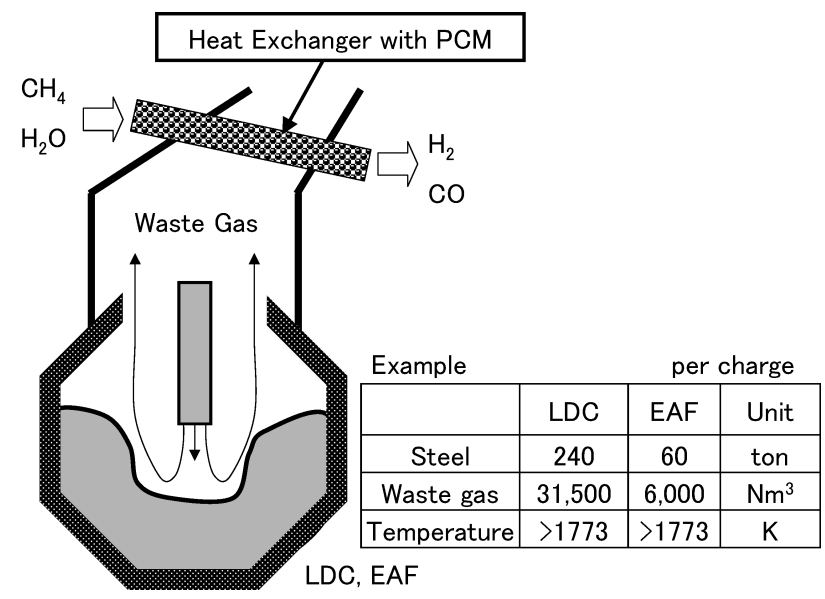

Fig. 1. Proposed heat recovery system for typical LDC and EAF gases in a methane-steam reforming process using a heat exchanger with PCM. 


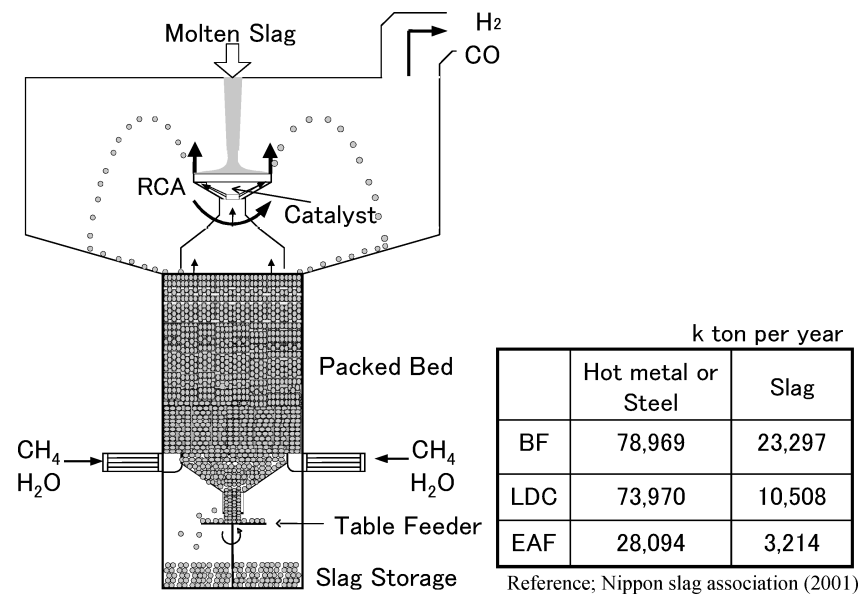

Fig. 2. Proposed heat recovery system of slag using a rotary cup atomizer.

study, ${ }^{4,7-9)}$ suggested a dry slag granulation process without water quenching. The possibility of developing a new process to recover the sensible and latent heats of molten slag at a temperature over $1773 \mathrm{~K}$, and to produce dry slag particles was discussed. Furthermore, the particle diameter of the granulated slag can be controlled, according to the requirement. The advantages of RCA are as follows:

(1) Dry granulation of a high-viscosity fluid such as oil is possible. ${ }^{4)}$

(2) Particle diameter can be easily controlled.

(3) The productivity of a unit equipment is very large.

(4) The sensible and latent heats of slag can be efficiently recovered by impinging reactive gases such as a mixture of methane and steam. ${ }^{4,8,11,12)}$

In the system of heat recovery from molten slag proposed in this study, molten slag is granulated using a RCA and then a packed bed made up of granulated slag is generated under the RCA as shown in Fig. 2. To enable heat recovery during the endothermic reaction, methane and water are introduced into the lower part of the packed bed. The packed bed preheats the steam and methane and then converts it into hydrogen and carbon monoxide in the help of a $\mathrm{Ni}$ based material as a catalyst at the bottom of the RCA.

\subsection{Calculation Method}

Figures 3 and 4 show the operating conditions used for the evaluation of the proposed systems, where the temperature and volume of waste used for the evaluation are assumed. High temperature waste is introduced into the heat exchanger where heat is recovered. The recovered heat is supplied to the steam-methane gas mixture which is the heat recovery medium and then changed into chemical energy through the endothermic reaction. Finally, with a drop in temperature, the waste flows out from the exchanger. The calculation is performed under the assumption that waste heat is recovered from a high temperature of waste to temperatures as low as $423 \mathrm{~K}$. The high temperatures of the wastes are 1723 and $1573 \mathrm{~K}$ for slag and gas, respectively. The slag heat is directly recovered by an endothermic reaction of methane steam reforming reaction, in contrast the heats of LDC gas and EAF gas are indirectly recovered through the latent heat storage by PCM.

The enthalpy and exergy changes per ton of crude steel

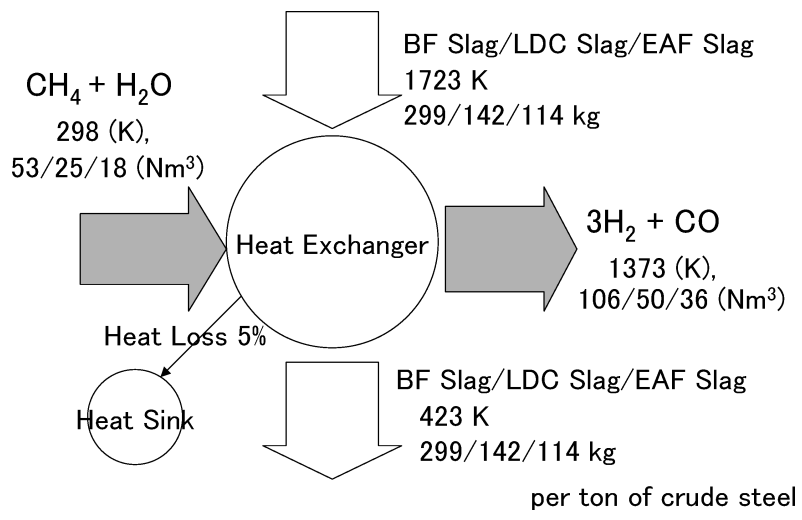

Fig. 3. Material and heat flow in the proposed system of slag heat recovery.

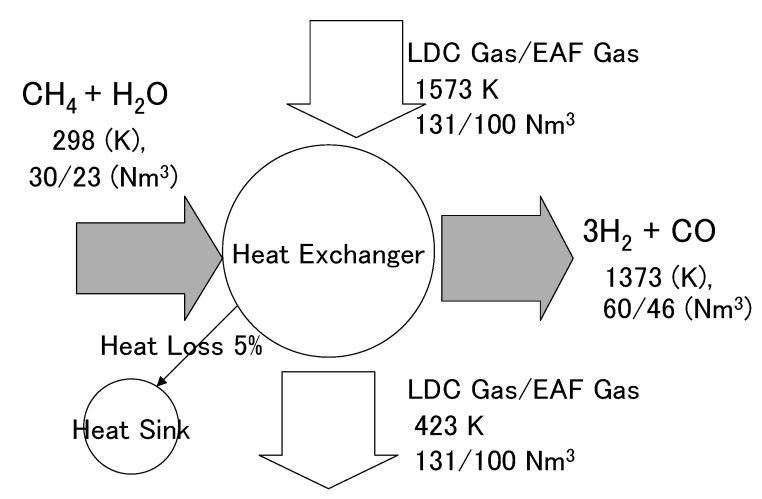

per ton of crude steel

Fig. 4. Material and heat flow in the proposed system of heat recovery from waste gas.

are calculated on the basis of the heat and material balances by modifying the enthalpy. In this calculation, the heat loss is assumed to be $5 \%$ of the inlet energy. The flow rate of methane and water is calculated based on the mass and heat balances of the heat exchanger. Exergy is used to evaluate the quality of energy change, from available to unavailable energy, that is, energy that cannot be utilized. To draw a comparison with conventional heat recovery methods such as sensible heat recovery, the system of hot water and steam generation are also evaluated. The effect of exergy loss on the temperature of the heat recovery medium is evaluated by performing calculations for five heat recovery systems. The five systems are un-recovered waste, hot water at $353 \mathrm{~K}$, steam at $473 \mathrm{~K}$, steam at $873 \mathrm{~K}$, and methane-steam reforming. Further, the amount of carbon dioxide emission, and the economic feasibility of these systems are evaluated, and compared.

According to the steelmaking industry, the value of waste gas is assumed to be US\$ 0.04 per $4.18 \mathrm{MJ}$ ( 1 Mcal) of combustion heat, excluding the cost of separation. Thus, from an economic and energy perspective, the above evaluation indicates a huge advantage, and is used as the basis for developing the proposed system.

\section{Results and Discussions}

Figure 5 shows the enthalpy changes in the five heat recovery systems. The figure shows that the total enthalpy for each system follows the first law of thermodynamics. The 


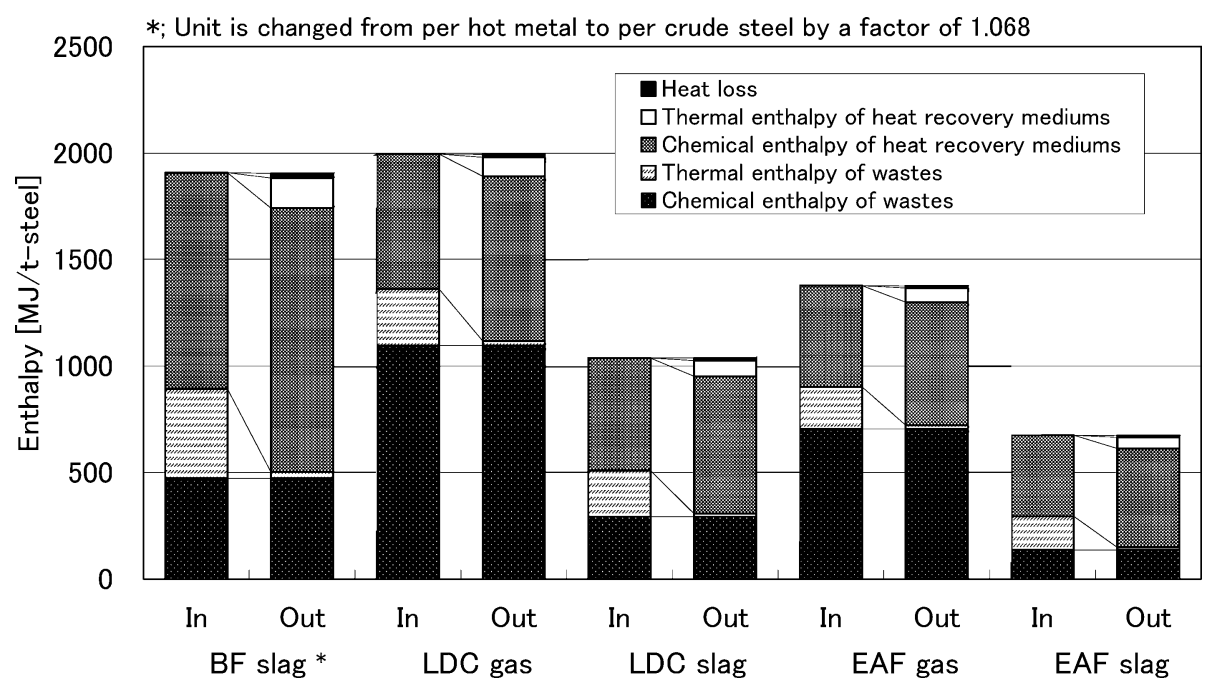

Fig. 5. Enthalpy changes for five systems before and after the heat recovery processes.

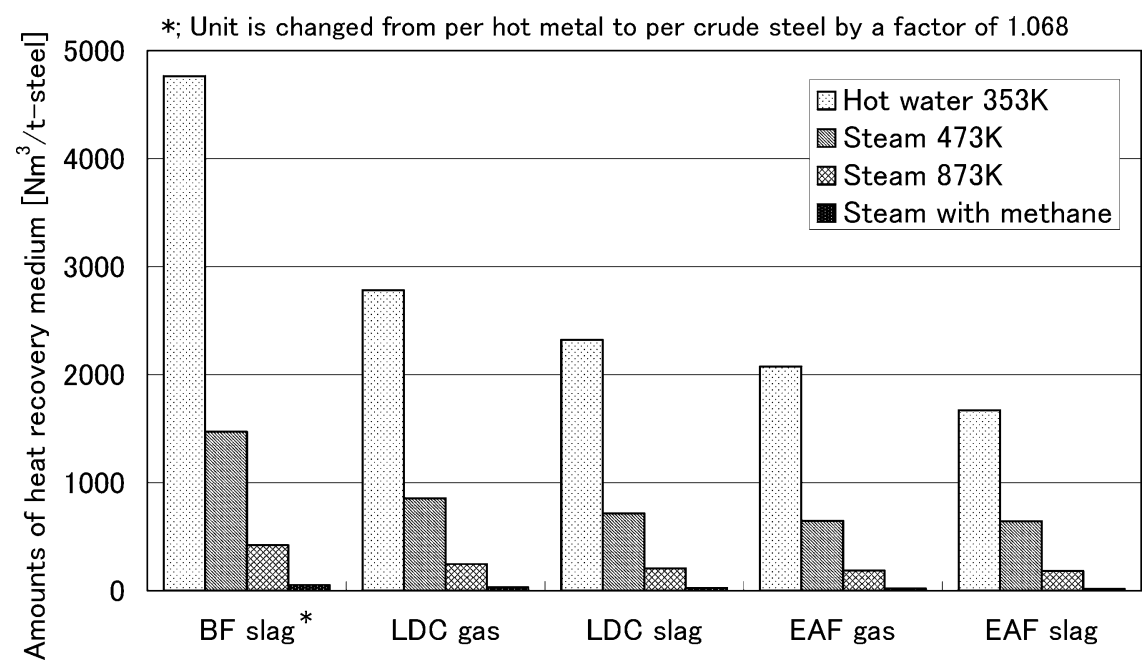

Fig. 6. Amount of heat recovery medium at various conditions for five systems.

fact that there is no change in the total enthalpy before and after the heat recovery process implies that the calculation agrees with the law of energy conservation. Among the five systems, BF slag and LDC gas have very large enthalpy values. This indicates that these two systems have a high energy potential. Since the calculation is based on available chemical composition, it can be assumed that the chemical composition of the wastes does not change during the heat recovery process, and the chemical enthalpy also does not change before and after heat recovery. In contrast, the thermal enthalpy of the wastes decrease and only a small amount remains at the end of the process. However, chemical enthalpy of the heat recovery medium increases as opposed to the thermal enthalpy of the wastes. This can be explained by the fact that heat from high temperature waste at $1773 \mathrm{~K}$ is used for an endothermic reaction during the methane-steam reforming process. As a result, thermal enthalpy changes to chemical enthalpy, as indicated by its increase after the heat recovery process. Moreover, the thermal enthalpy of the waste is also changed into thermal enthalpy of the heat recovery medium due to an increase in temperature. Waste heat is utilized from a temperature of 1773 to $423 \mathrm{~K}$. At the end of the process the thermal en- thalpy corresponds to the value at $423 \mathrm{~K}$ and a $5 \%$ heat loss. These results show that the thermal enthalpy of the wastes can change into thermal and chemical enthalpy of the reaction gas.

Figure 6 shows the amount of the heat recovery medium needed for recovering waste heat. Four mediums are used in this evaluation, hot water at $353 \mathrm{~K}$, steam at $473 \mathrm{~K}$, steam at $873 \mathrm{~K}$ and methane-steam reforming. The enthalpies of BF slag and LDC gas are higher than the other three, which implies that they need a large heat recovery medium. The figure shows that about $4763 \mathrm{~kg}$ of water per ton of crude steel is required for recovering waste heat of BF slag when the hot water at $353 \mathrm{~K}$ system is used. However, as the steam at 473 and $873 \mathrm{~K}$ systems are used, the amount of medium needed decreases to approximately 1469 and 422 $\mathrm{kg}$, respectively. Similar results are obtained for the other waste materials where the ratio of the consumption of heat recovery medium in each system is $1: 0.3: 0.09$ (Hot water $353 \mathrm{~K}$ : Steam $473 \mathrm{~K}$ : Steam $873 \mathrm{~K}$ ). Additionally, heat recovery using the methane-steam reforming system, which is conducted at a temperature over $1173 \mathrm{~K}$ needs only $52 \mathrm{~kg}$ of medium per ton of crude steel or about $99 \%$ less than that required for the hot water system. This phenomenon 


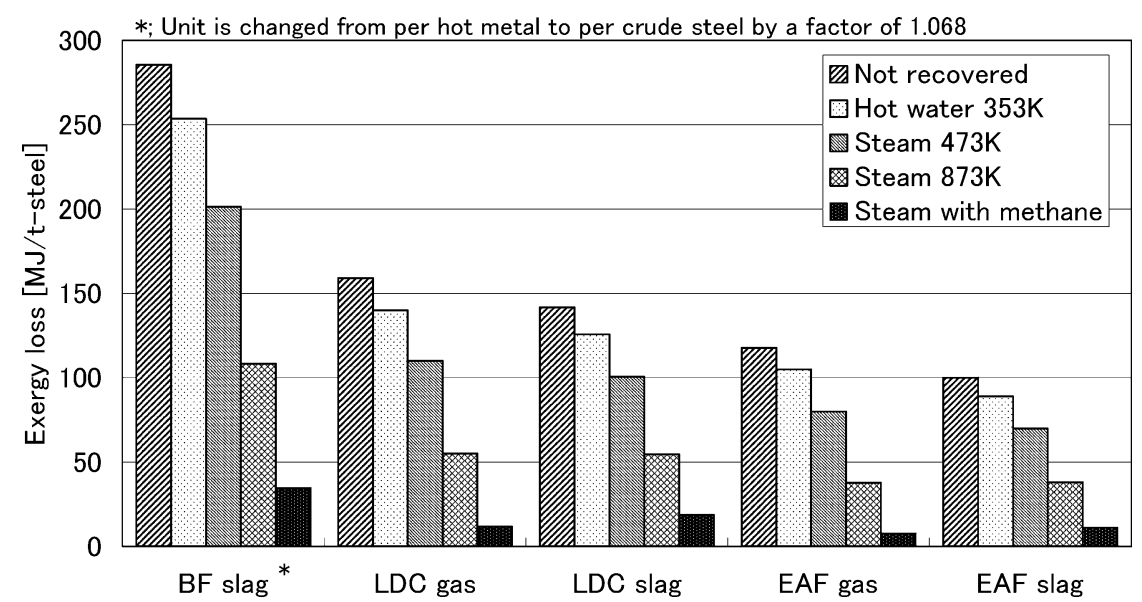

Fig. 7. Exergy losses at various conditions for five systems

indicates that as the temperature of the heat recovery medium decreases, the quality of thermal energy also decreases because the amount of heat recovery medium needed is large. Consequently, thermal energy is dispersed and the quality of thermal energy per unit volume decreases. In other words, in the heat recovery systems using hot water and steam, high quality waste heat is converted into a low quality heat source. In contrast, in the system using an endothermic reaction, thermal energy changes to chemical energy without a significant energy quality loss suggesting that this system has greater potential than the others.

To clarify the effective use of the heat recovery medium, the exergy loss is also analyzed and compared for each system. Figure 7 shows the exergy losses of the proposed systems at various conditions. Generally, exergy losses show a similar trend in terms of the amount of medium needed to recover the heat from each system. The exergy loss of the waste gas is higher than that of slag both for LDC and EAF. Figure 5 also shows that the total enthalpy for the waste gas is more than that for slag. BF slag has the highest exergy loss, about $286 \mathrm{MJ}$ per ton of crude steel. When using the hot water at $353 \mathrm{~K}$ system, about $254 \mathrm{MJ}$ per ton of crude steel is lost, that is, only $12 \%$ of the available energy in the slag is recovered despite its large potential. However, when the heat is recovered by the methane-steam reforming system using an endothermic reaction, the exergy loss is only $35 \mathrm{MJ}$ per ton of crude steel. This value indicates that the exergy loss in this system is approximately only $12 \%$ as compared to the unrecovered system. Similar results are obtained for the other waste materials including LDC gas, LDC-slag, EAF-gas and EAF-slag. Accordingly, exergy changes sharply in relation to the temperature of the heat recovery medium. As the temperature of the heat recovery medium increases, the exergy loss decreases. Thus, the heat recovery system using an endothermic reaction is expected to show the minimal exergy loss. In other words, recovering high temperature waste heat by using a low temperature medium resulted in low quality energy. However, recovery using a high temperature medium such as methane-steam reforming which is a highly endothermic reaction provides productive and high quality energy.

Table 1 shows the predicted values for maximum recovered heat and reduction of carbon dioxide emission which is expected by this heat recovered. The results show that the
Table 1. Predicted values for maximum heat recovery and reduction in carbon dioxide emission.

\begin{tabular}{|c|c|c|c|c|c|}
\hline \multirow{2}{*}{\multicolumn{2}{|c|}{ Item }} & \multirow{2}{*}{$\begin{array}{c}\text { Recovered heat } \\
{[\mathrm{MJ} / \mathrm{t} \text {-steel }]}\end{array}$} & \multicolumn{2}{|c|}{ Amount of $\mathrm{CO}_{2}$} & \multirow{2}{*}{$\frac{\eta}{(\%)}$} \\
\hline & & & [C-kg/t-steel] & [C-k ton/year] & \\
\hline \multicolumn{2}{|c|}{ B F Slag } & 394 & 12.1 & 835 & 1.6 \\
\hline \multirow{3}{*}{ LDC } & Slag & 192 & 5.9 & 436 & 0.8 \\
\hline & Gas & 230 & 7.0 & 518 & 1.0 \\
\hline & Slag & 138 & 4.2 & 118 & 0.2 \\
\hline EAF & Gas & 171 & 5.2 & 146 & 0.3 \\
\hline \multicolumn{2}{|c|}{ Total } & - & - & 2053 & 3.9 \\
\hline
\end{tabular}

heat recovered from BF slag, approximately $394 \mathrm{MJ}$ per crude steel, is the largest among the five systems. The high temperature and large volume of BF slag correspond to the large amount of heat available for recovery. The amount of carbon dioxide emitted by the combustion of carbon is calculated by dividing the recovered heat of wastes by the combustion heat of carbon. Since the temperature of waste gas is higher than that of slag, the heat is recovered at a higher temperature and involves a substantial decrease in carbon dioxide emission. Presently, $500 \mathrm{~kg}$ of carbon dioxide is discharged from a BF-LDC per ton of crude steel. The total reduction of carbon dioxide emission based on carbon by heat recovery from BF and LDC wastes is calculated as about $25 \mathrm{C}-\mathrm{kg}$ per ton of crude steel. This value corresponds to $5 \%$ of the present fuel ratio. If this system is applied to the entire Japanese steelmaking industry with the assumption that the total crude steel production is $102 \mathrm{M}$ ton (see Fig. 2), using a combination of BF, LDC and EAF, the amount of carbon dioxide emission, based on carbon, decreases by $2.05 \mathrm{M}$ ton per year. This value means as much as $3.9 \%$ reduction of $\mathrm{CO}_{2}$ emission in comparison to 1990.

Table 2 shows the economic evaluation of the steam reforming reaction for waste heat recovery. In this system, the reaction used for methane-steam reforming is an endothermic reaction in which methane and water are converted into hydrogen and carbon monoxide. The results show that the combustion heat increases from $801 \mathrm{~kJ}$ for methane gas to $1011 \mathrm{~kJ}$ per $\mathrm{mol}-\mathrm{CH}_{4}$ in the steam reforming reaction. This results in a cost benefit of US\$ 0.002 per $\mathrm{mol}_{-} \mathrm{CH}_{4}$. In the 
Table 2. Predicted cost benefit from reformed gas in the proposed systems

\begin{tabular}{|c|c|c|c|c|c|c|c|}
\hline & & & $\begin{array}{l}\mathrm{CH}_{4}+ \\
\mathrm{H}_{2} \mathrm{O}\end{array}$ & $\rightarrow$ & $\begin{array}{c}3 \mathrm{H}_{2}+ \\
\mathrm{CO}\end{array}$ & $\Delta$ & Unit \\
\hline & & \multirow{2}{*}{$\begin{array}{c}1 \mathrm{~mol}- \\
\mathrm{CH}_{4}\end{array}$} & 801 & $\rightarrow$ & 1011 & +120 & $\mathrm{~kJ}$ \\
\hline & & & 0.0076 & $\rightarrow$ & 0.0096 & +0.002 & $\$$ \\
\hline & & $\begin{array}{c}1 \mathrm{Nm}^{3-} \\
\mathrm{CH}_{4}\end{array}$ & 0.34 & $\rightarrow$ & 0.43 & +0.09 & $\$$ \\
\hline \multirow{2}{*}{$\mathrm{BF}$} & \multirow{2}{*}{ Slag } & $1 \mathrm{t}$-steel & 8.9 & $\rightarrow$ & 11.3 & +2.4 & $\$$ \\
\hline & & 1 year & $655 \times 10^{6}$ & $\rightarrow$ & $829 \times 10^{6}$ & $+174 \times 10^{6}$ & $\$$ \\
\hline \multirow{4}{*}{ LDC } & \multirow{2}{*}{ Slag } & $1 \mathrm{t}$-steel & 4.3 & $\rightarrow$ & 5.4 & +1.1 & $\$$ \\
\hline & & 1 year & $318 \times 10^{6}$ & $\rightarrow$ & $399 \times 10^{6}$ & $+81 \times 10^{6}$ & $\$$ \\
\hline & \multirow{2}{*}{ Gas } & $1 \mathrm{t}$-steel & 5.1 & $\rightarrow$ & 6.5 & +1.4 & $\$$ \\
\hline & & 1 year & $377 \times 10^{6}$ & $\rightarrow$ & $481 \times 10^{6}$ & $+104 \times 10^{6}$ & $\$$ \\
\hline \multirow{4}{*}{ EAF } & \multirow{2}{*}{ Slag } & $1 \mathrm{t}$-steel & 3.1 & $\rightarrow$ & 3.9 & +0.8 & $\$$ \\
\hline & & 1 year & $87 \times 10^{6}$ & $\rightarrow$ & $109 \times 10^{6}$ & $+22 \times 10^{6}$ & $\$$ \\
\hline & \multirow{2}{*}{ Gas } & $1 \mathrm{t}$-steel & 3.9 & $\rightarrow$ & 4.9 & +1.0 & $\$$ \\
\hline & & 1 year & $110 \times 10^{6}$ & $\rightarrow$ & $138 \times 10^{6}$ & $+28 \times 10^{6}$ & $\$$ \\
\hline Total & & 1 year & $1547 \times 10^{6}$ & $\rightarrow$ & $1956 \times 10^{6}$ & $+409 \times 10^{6}$ & $\$$ \\
\hline
\end{tabular}

Table 3. Maximum cost benefit from granulated slag.

\begin{tabular}{|c|c|c|c|c|c|c|}
\hline & & Conventional & $\rightarrow$ & Proposed & $\Delta$ & Unit \\
\hline \multirow{2}{*}{ BF slag } & 1 ton & -10 & $\rightarrow$ & +20 & +30 & $\$$ \\
\cline { 2 - 7 } & 1 year & $-232 \times 10^{6}$ & $\rightarrow$ & $+464 \times 10^{6}$ & $+696 \times 10^{6}$ & $\$$ \\
\hline $\begin{array}{c}\text { LDC } \\
\text { slag }\end{array}$ & 1 ton & -15 & $\rightarrow$ & +20 & +35 & $\$$ \\
\hline & 1 year & $-157 \times 10^{6}$ & $\rightarrow$ & $+210 \times 10^{6}$ & $+367 \times 10^{6}$ & $\$$ \\
\hline \multirow{2}{*}{$\begin{array}{c}\text { EAF } \\
\text { slag }\end{array}$} & 1 ton & -20 & $\rightarrow$ & $\begin{array}{c}+400^{*} \\
+50^{* *}\end{array}$ & $\begin{array}{c}+420^{*} \\
+70^{* *}\end{array}$ & $\$$ \\
\cline { 2 - 7 } & 1 year & $-64 \times 10^{6}$ & $\rightarrow$ & $\begin{array}{c}+750 \times 10^{6 *} \\
+68 \times 10^{* * *}\end{array}$ & $+882 \times 10^{6}$ & $\$$ \\
\hline
\end{tabular}

present BF-LDC method, the cost benefit of reformed gas corresponds to US\$ 4.9 per ton of crude steel produced. If this system is applied to the entire steelmaking industry, for the production of $102 \mathrm{M}$ ton of crude steel, the cost benefit of reformed gas amounts to US\$ 409 million per year.

Table 3 shows the cost benefits of the granulated slags. Presently, most of the BF slag is disposed as waste material and approximately US\$ 10 is spent per ton of BF slag. In contrast, if the slag is granulated for example, by RCA, and used as an abrasive material, it will offer the steel industry a cost benefit of approximately US\$20 per ton of slag discharged. In other words, BF slag granulation using RCA increases its value by US\$ 30 per ton of slag, regardless of heat recovery. The granulated EAF slag is very valuable. In the case of EAF slag, the cost benefit is about US\$ 490 per ton of slag or US\$ 882 million per year. Currently, approximately US\$ 453 million is spent per year for treating all the slags, and the sensible heat is wasted. This study shows that if the slag is completely utilized, both the slag and its sensible heat after recovery will offer the steelmaking industry a cost benefit of approximately US\$ 1945 million per year. Thus, this study demonstrates the feasibility of treating the waste gases and slag from steelmaking industries by the proposed method and indicates the possibility of solving an environmental problem besides offering substantial cost benefits to the steelmaking industry.

\section{Conclusions}

The feasibility study of high temperature waste heat recovery using an endothermic reaction has been carried out on the basis of material and energy balances. This study reports the following conclusions:

(1) The method using an endothermic reaction such as methane steam reforming reported the least exergy loss, in comparison with conventional methods such as hot water or steam production.

(2) The reduction in carbon dioxide emission due to the proposed system is as high as $2.05 \mathrm{M}$ ton per year in Japanese steelmaking industry.

(3) The cost benefits incurred by the proposed method, based on the steam reforming reaction, amount of total US\$ 409 million and US\$ 1945 million per year for discharged gas and slag, respectively.

\section{REFERENCES}

1) T. Akiyama, R. Takahashi and J. Yagi: ISIJ Int., 29 (1989), 447.

2) T. Akiyama, H. Sato, A. Muramatsu and J. Yagi: ISIJ Int., 33 (1993), 1136.

3) A. Muramatsu, H. Sato, T.Akiyama and J. Yagi: ISIJ Int., 33 (1993), 1144.

4) E. Kasai, T. Kitajima, T. Akiyama, J. Yagi and F. Saito: ISIJ Int., 37 (1997), 1031.

5) T. Akiyama and J. Yagi: ISIJ Int., 38 (1998), 896.

6) T. Akiyama, K. Oikawa, T. Shimada, E. Kasai and J. Yagi: ISIJ Int., 40 (2000), 285.

7) T. Shimada, T. Akiyama, E. Kasai and J. Yagi: ISIJ Int., 40 (2000), 958.

8) T. Simada, V. Kochura, T. Akiyama, E. Kasai and J. Yagi: ISIJ Int., 41 (2001), 111.

9) T. Mizuochi, T. Akiyama, T. Simada, E. Kasai and J. Yagi: ISIJ Int., 41 (2001), 1423.

10) T. Akiyama and J. Yagi: TokuKaiHei, Japanese patent 11-23172, (1999).

11) N. Maruoka, K. Sato, J. Yagi and T. Akiyama: ISIJ Int., 42 (2002), 215.

12) N. Maruoka and T. Akiyama: ISIJ Int., 42 (2002), 1189.

13) N. Maruoka, M. Asao, T. Miyako, M. Nakamoto and T. Akiyama: JCEJ., 28 (2002), 713.

14) N. Maruoka and T. Akiyama: JCEJ., 36 (2003), 794

15) T. Akiyama, Y. Ashizawa and J. Yagi: Trans. Jpn. Soc. Mech. Eng., 57B (1991), 284.

16) T. Akiyama and J. Yagi: High Temp. Mater. Process., 19 (2000), 219 